Res., Soc. Dev. 2019; 8(2):e582550

ISSN 2525-3409 | DOI: http://dx.doi.org/10.33448/rsd-v8i2.550

\title{
Sistema Prisional do Brasil e o Papel do CNJ na Promoção da Eficácia dos Direitos
}

Humanos

Prison System of Brazil and the Role of the CNJ in Promoting Human Rights Effectiveness

\section{Sistema Prisional de Brasil y el Papel del CNJ en la Promoción de la Eficacia de los Derechos Humanos}

\section{Semyramis Moura Duarte} Universidade Federal de Campina Grande-UFCG, Brasil

E-mail: myrahduarte@hotmail.com

\section{Vanessa Érica da Silva Santos}

ORCID: https://orcid.org/0000-0003-0994-0894 Universidade Federal de Campina Grande-UFCG, Brasil

E-mail: vanessa.erica@ hotmail.com

Recebido: 06/08/2018 - Aceito: 12/08/2018

\section{Resumo}

Analisa-se, criticamente, a dinâmica dos direitos humanos, a partir da plataforma democrática brasileira instaurada com a Constituição Federal de 1988. Com isso, aponta-se os limites do regime democrático como campo para o reconhecimento e a afirmação dos direitos humanos, no Brasil, em aplicação concomitante com a legislação penal vigente. Para tanto, a investigação parte da crítica à teoria dos Direitos Humanos em relação à efetividade, no que se refere à política criminal. Conforme muitas vezes é apresentado pelos veículos de comunicação, os direitos humanos são tidos como "direitos do bandido". Esta deturpação ocorre talvez pela falha na legislação penal onde os direitos humanos, pela sua própria natureza, são talvez mais bem elaborados e definidos do que a legislação penal brasileira. Problemas estruturais talvez sejam a resposta para tal distorção. O CNJ vem realizando um trabalho de mobilização para solucionar a problemática nos presídios brasileiros. Neste cenário, em que muitos acham que os Direitos Humanos comprometem a eficiência da penal, o presente trabalho será realizado pelo método dedutivo, através de pesquisas bibliográficas, artigos científicos e periódicos especializados, para identificar a verdadeira causa do problema. Para tanto, o presente trabalho objetiva refletir sobre esses aspectos e apontar possíveis soluções para a harmonização da efetivação dos direitos humanos em concomitância 
com a aplicação efetiva da pena. Os resultados obtidos na pesquisa demonstram a necessidade de políticas públicas e de justiça restaurativa de concientização da população acerca da necessidade de ressocialização do apenado e do Estado garantidor de direitos fundamentais do apenado, como uma forma efetiva de promoção de justiça e bem estar social.

Palavras-chave: Direitos humanos; Sistema prisional; Eficácia; Estado.

\begin{abstract}
The dynamics of human rights are critically analyzed, based on the Brazilian democratic platform established with the Federal Constitution of 1988. With this, the limits of the democratic regime as a field for the recognition and affirmation of human rights are pointed out. Brazil, in concurrent application with the current criminal legislation. To do so, the investigation starts from the critique of the Human Rights theory in relation to the effectiveness, with regard to criminal policy. As often depicted by the media, human rights are seen as "bandit rights." This misrepresentation is perhaps due to the failure of criminal legislation where human rights, by their very nature, are perhaps better elaborated and defined than Brazilian criminal law. Structural problems may be the answer to such distortion. The CNJ has been carrying out a mobilization work to solve the problem in the Brazilian prisons. In this scenario, in which many believe that Human Rights compromise the efficiency of the criminal, the present work will be carried out by the deductive method, through bibliographical research, scientific articles and specialized periodicals, to identify the true cause of the problem. Therefore, the present work aims to reflect on these aspects and to point out possible solutions for the harmonization of the implementation of human rights in concomitance with the effective application of the sentence. The results obtained in the research demonstrate the need for public policies and restorative justice to raise public awareness about the need for resocialization of the victim and the State guaranteeing the fundamental rights of the victim as an effective way of promoting justice and social welfare.
\end{abstract}

Keywords: Human rights; Prison system; Effectiveness; State.

\title{
Resumen
}

Se analiza, críticamente, la dinámica de los derechos humanos, a partir de la plataforma democrática brasileña instaurada con la Constitución Federal de 1988. Con ello, se apunta los límites del régimen democrático como campo para el reconocimiento y la afirmación de los derechos humanos, Brasil, en aplicación concomitante con la legislación penal vigente. Para ello, la investigación parte de la crítica a la teoría de los derechos humanos en relación a la efectividad, en lo que se refiere a la política criminal. A menudo es presentado por los medios de comunicación, los derechos humanos son considerados como "derechos del bandido". Esta 
tortura ocurre tal vez por el fallo en la legislación penal donde los derechos humanos, por su propia naturaleza, son quizás más bien elaborados y definidos que la legislación penal brasileña. Los problemas estructurales pueden ser la respuesta a tal distorsión. El CNJ viene realizando un trabajo de movilización para solucionar la problemática en los presidios brasileños. En este escenario, en que muchos creen que los derechos humanos comprometen la eficiencia de la penal, el presente trabajo será realizado por el método deductivo, a través de investigaciones bibliográficas, artículos científicos y periódicos especializados, para identificar la verdadera causa del problema. Para ello, el presente trabajo objetiva reflexionar sobre esos aspectos y apuntar posibles soluciones para la armonización de la efectividad de los derechos humanos en concomitancia con la aplicación efectiva de la pena. Los resultados obtenidos en la investigación demuestran la necesidad de políticas públicas y de justicia restaurativa de concientización de la población acerca de la necesidad de resocialización del apenado y del Estado garante de derechos fundamentales del apenado como una forma efectiva de promoción de justicia y bienestar social.

Palabras clave: Derechos humanos; Sistema prisional; eficacia; Estado.

\section{Introdução}

Desde o início das civilizações, a convivência harmoniosa em sociedade foi possível com criação das diretrizes de comportamento. Embora ainda existam sociedades submetidas a regimes ditatoriais ou não democráticos, modernamente, essas diretrizes devem ser ditadas pelos Poderes regularmente constituídos.

No âmbito penal, destaca-se o chamado ius puniendi, que, em sentido objetivo, é entendido como o Estado cria normas de natureza penal, através de seu Poder Legislativo, mediante o sistema de freios e contrapesos, exercido pelo Poder Executivo, proibindo ou impondo determinado comportamento sob ameaça de uma sanção. Subjetivamente, isso ocorre quando esse mesmo Estado, através de seu poder Judiciário, executa suas decisões contra alguém que descumpriu o comando normativo, praticando uma infração penal, ou seja, fato típico, ilícito e culpável.

Desta forma, somente com este raciocínio um Estado Democrático de Direito poderá oferecer segurança necessária aos seus cidadãos, onde o ius puniendi evidencia a sua validade.

Importante é destacar que, sem dúvida, a característica das sociedades modernas é a exclusividade do poder de punir que é atribuído ao Estado, o que não impede que o particular articule, em juízo, o seu iusaccusationis, nas ações penais, em que a iniciativa é de natureza 
privada. Esta autoafirmação do Estado entretanto não é absoluta, visto que este ente deverá agir segundo certos parâmetros constitucionais, conforme os seguintes dispositivos constitucionais:

[...] não há crime sem lei anterior que o defina (art.5, XXXIX); [...] a lei não excluirá da apreciação do Poder Judiciário lesão ou ameaça a direito (art. $\left.5^{\circ}, \mathrm{XX}\right)$; [...] ninguém será processado nem sentenciado senão pela a utoridade competente (art. $5^{\circ}$, LII); [...] ninguém será privado da liberdade ou de seus bens sem o devido processo legal (art.5 $5^{\circ}$ LIV).

Assim, os direitos fundamentais cumprem função de defesa dos direitos dos cidadãos, sob dupla perspectiva, por serem normas de competência negativa para os poderes públicos, ou seja, que não lhes permitem a ingerência na esfera jurídica individual, e por implicarem um poder, que se conferem ao indivíduo, não só para que se exerçam tais direitos positivamente, más também que se exija, aos poderes públicos, a correção das omissões relativas. Consistem, portanto, na limitação do poder do Estado de interferir na vida dos indivíduos e ao mesmo tempo conferindo prerrogativas aos particulares de pleitearem ações estatais que contemplarem seus direitos.

Os direitos humanos, Estado de Direito e o ius puniendi são expressões interligadas, sendo, portanto, elo de uma mesma corrente. A limitação no poder de punir do Estado juntamente com a aplicação dos direitos humanos, quando evidenciadas na aplicação da pena, muitas vezes, sofre um impasse com relação ao sentimento de justiça intrínseco à consciência humana.

A quebra desses princípios, norteadores da vida humana, provoca o desequilíbrio, a discórdia, o conflito, a ausência da paz social, trazendo como consequência, a indignação, o inconformismo, a busca da restauração através do amparo jurisdicional, do bem jurídico lesado, a quem de direito. Isto talvez ocorra pelo falto de modernamente a palavra sanção ter significado de castigo, punição, deixando de lado o caráter social da pena.

No Brasil, principalmente, tem-se ocorrido diversas críticas no que se refere à aplicação dos direitos humanos àqueles que cometem delitos. Chamado inúmeras vezes de “direitos dos bandidos", os direitos humanos vão de encontro à legislação penal brasileira, que é falha, o que reduz consideravelmente sua eficiência no valor social da pena.

Para tanto, o presente trabalho buscará refletir sobre esses aspectos e apontar possíveis soluções para a harmonização da efetivação dos direitos humanos em concomitância com a aplicação efetiva da pena. 


\section{Metodologia}

Para alcançar os objetivos traçados, a presente pesquisa utilizará como método de abordagem o dedutivo, tendo em vista que se buscará os resultados a partir da análise geral até concluir de maneira particular a hipótese. Quanto à natureza da pesquisa será aplicada, pois buscará trazer soluções que podem ser aplicadas ao caso concreto; Quanto aos objetivos gerais será descritiva pois buscará identificar os fatores que trazem ineficácia aos direitos humanos no sistema prisional; Por fim, quanto aos procedimentos técnicos será realizado por meio de pesquisa bibliográfica e documental, pois se buscará através da renomada doutrina do direito e periódicos especializados, bem como através da interpretação das leis buscar a solução para dar efetividade aos direitos humanos.

\section{Direitos Humanos: Aspectos Gerais}

Alguns aspectos que fazem referência à teoria geral dos direitos humanos, destacando suas características e evolução histórica. Assim, demonstrar-se-á o poder punitivo do Estado e, também, suas garantias que, muitas vezes, se confrontam com a política penal, sobretudo, em face da falta de estrutura no cárcere para reinserção do apenado no meio social.

\subsection{Direitos humanos: conceitos e características em relação à pena}

A evolução dos diretos humanos, na humanidade, ocorreu de forma bastante morosa, visto que a origem dos direitos humanos partiu de conceitos filosóficos como direito natural. O direito, como fruto do poder supremo de Deus, norteou por muito tempo os direitos humanos já que não havia uma distinção entre os mesmos e os direitos naturais, exatamente por entender que o homem é a causa de toda evolução desde a era primitiva até se adequar aos moldes sociais.

As várias fases evolutivas, como informa Oliveira (2011), se iniciam com os direitos do homem à vida e à dignidade humana, em seguida passou a ser chamado de direitos fundamentais por estarem positivados na constituição e, finalmente, ganhou contexto internacional, sendo denominado, portanto, de direitos humanos, especialmente, pela edição normativa de caráter global como tratados, convenções, resoluções, protocolos, dentre outros.

Os direitos humanos podem ser considerados como garantias que o sistema jurídico dá 
a todos, sem restrições. Trata-se das garantias inerentes à condição do ser humano inseridas na Constituição do Estado, passando a ser conhecidos como direitos fundamentais aos quais foram reconhecidos por pelas convenções e tratados internacionais. Logo, a expressão direitos humanos assume um caráter fluido, aberto e de contínua redefinição, de modo que pode referir-se à situações políticas, sociais e culturais.

A respeito disso, Gilmar Mendes (2008) assevera que nem todos os direitos fundamentais se adéquam plenamente a essas características, de modo que seria impróprio afirmar que todas as pessoas são titulares de direitos fundamentais e que a qualidade de ser humano constitui condição suficiente para a titularidade de tantos desses direitos. Sobretudo, alguns direitos fundamentais específicos não se ligam a toda e qualquer pessoa. Embora grande parte deles refira-se a todas as pessoas - como o direito à vida - há posições que não interessam a todo indivíduo, referindo-se apenas a alguns - aos trabalhadores por exemplo.

Já os direitos humanos correspondem à dignidade de cada pessoa, sendo que esta não é dada pelo Estado, mas pelo simples fatos do indivíduo ser humano. Em outras palavras, conforme Nino, a expressão "direitos humanos" significa que tais direitos têm como beneficiários todos os seres humanos e nada mais do que eles, pois sua única condição de aplicação é a de o sujeito constituir em um ser humano - situação essa necessária e suficiente -, para gozar de tais (1989, p.41, apud WEIS 2010, p. 25).

Ademais, cada pessoa deve ser respeitada igualmente independentemente de raça, cor ou sexo, e ter protegido aquilo se chama de direito fundamental inerente a todo ser humano, para que tenham condições necessárias para desenvolver -se de forma apropriada, o que é indispensável à existência humana, e reconhecido universalmente por todas as sociedades pela sua proteção pelos tratados e convenções entre os Estados.

Sem dúvida, essa é a verdadeira essencialidade dos direitos humanos. Nos termos da nossa Magna Carta, toda liberdade garantida ao ser humano deve ser tratada como um direito fundamental, logo, na lição de Pedro Lenza (2007), o direito à vida, previsto de forma genérica no art. $5^{\circ}$, caput, abrange tanto o direito de não ser morto, privado da vida, portanto, o direito de continuar vivo, como também o direito de ter uma vida digna com segurança pessoal principalmente para proteger o indivíduo de sua integridade física e moral, compreendendo tanto a segurança pública como lesões desarrazoadas pelo Estado.

$3.2 \mathrm{O}$ poder de punir do Estado e a proteção à integridade física e psicológica do apenado 
ISSN 2525-3409 | DOI: http://dx.doi.org/10.33448/rsd-v8i2.550

Os vários diplomas legais existentes, no Brasil, preveem garantias ao apenado durante todo o cumprimento da pena, assim como a aplicação dos direitos humanos em seu favor. As várias convenções existentes em nível mundial, como a Declaração Americana de Direitos e Deveres do Homem, a Declaração Universal dos Direitos Humanos e a Resolução da ONU dispõem sobre regras mínimas de tratamento do apenado.

Constitucionalmente, há garantias também reservadas no artigo $5^{\circ}$ da Magna Carta, que trata dos direitos e garantias fundamentais. Infraconstitucionalmente, tem-se a proteção dessas garantias também pela Lei de Execução Penal brasileira (LEP), mais precisamente sobre os direitos do preso nos incisos I ao XIV do seu artigo 41.

Com as legislações existentes sobre o tema, que garantem a integridade física e moral do preso, a execução penal assume importância ainda maior sobre os parâmetros do convívio social. A própria lei determina os legitimados a prosseguir com a pretensão executória, como também relaciona a sociedade como partícipe do processo de execução da pena, evidenciando, portanto, um duplo paradigma, onde o Estado garante o cumprimento interno do cárcere e administra a pena do recluso, de modo que proporcione o fiel cumprimento da sentença, bem como, deixa-o na condição de egresso no sistema. Assim, Mirabete (2007, p. 30) leciona:

Segundo consta da exposição de motivos, aliás, o principio da legalidade domina o corpo e o espírito da lei, de forma a impedir que o excesso ou o desvio da execução comprometam a dignidade e a humanidade do Direito Pena.

Logo, a responsabilidade do Estado sobre o preso permeia desde privação da liberdade, em face do seu direito de punir, abrangendo a estruturação e manutenção dos presídios, e, mais importante, a integridade física e moral do enclausurado.

À luz da Lei de Execuções Penais brasileira, é modelo de legislação do tema para qualquer outro país, admirável e reconhecida mundialmente, pelo seu caráter humanitário e legalista, abraçando os direitos fundamentais e sociais de maneira louvável. Todavia, grande parte desse texto é apenas letra morta. Há um total desprezo a LEP brasileira, de modo que diariamente percebe-se o descaso e o desrespeito com a legislação e principalmente com o apenado.

Mais do que punir, o Estado deve zelar pelo respeito a dignidade humana e primar pelo caráter humanitário da pena garantida pelo legislador quando criou-se a LEP.

Os Estados deverão repudiar qualquer espécie de tortura, pois esta é uma medida que 
obstrui por completo os direitos humanos. As leis igualmente deverão ser editadas no sentido de reprimir a prática de tais métodos ardilosos, não se podendo tolerar atos que como este, violem brutalmente a dignidade do ser humano.

Diante disto, não se pode deixar de lado uma das máximas do processo penal, a de que todo acusado é considerado inocente até ser declarado culpado e se julgar-se indispensável prendê-lo, todo o rigor desnecessário à guarda de sua pessoa deve ser severamente punido pela lei e que nenhuma pessoa sujeita a qualquer forma de detenção ou prisão será submetida à tortura ou à penas ou tratamentos cruéis, desumanos ou degradantes (GRECO, 2011).

Capez (2008) demonstra a importância do desenvolvimento das leis penais, de modo que a partir do momento em que o cidadão sai de seu estado natural para viver em sociedade, este mesmo abdica parte de sua liberdade em prol da coletividade, tendo, também, que admitir-se a um governo capaz de promover garantias mínimas de proteção contra possíveis danos ao convívio social, devendo o indivíduo ser punido apenas quando agir de forma delinquente ou em desacordo com o que estiver previsto em lei. Em outras palavras, o cidadão dever renunciar, voluntariamente, de alguns costumes naturais para ter resguardado direito e garantias constitucionais previstos, sendo necessário o zelo dessas garantias pelo próprio Estado e a não ocorrência de excessos nas punições.

\subsection{A ressocialização do egresso}

O Estado, garantidor da eficácia dos direitos fundamentais, é, também, o maior responsável pelo controle dos valores fundamentais da sociedade. Este, através do direito penal, estipula punições para certas condutas descritas no tipo penal onde o transgressor das normas passará por um período de reflexão com o objetivo de restabelecer-se ao convívio social. Essa forma preventiva de conduta proveniente do Estado é o que garante o bem estar social e impeça a transgressão das normas. Assim, Jesus (2009, p. 3) expõe:

[...] o Estado estabelece sanções, procurando tornar invioláveis aos bens que protege. Ao lado dessas sanções o Estado também fixa outras medidas com o objetivo de prevenir ou reprimi r a ocorrência de fatos lesivos dos bens jurídicos dos cidadãos. A mais severa das sanções é a pena, estabelecida para o caso de inobservâncias de um imperativo.

Logo, o Estado deve punir o transgressor, assim que houver a violação da ordem jurídica. Entretanto, essa punição deverá seguir o devido processo legal, observando sempre 
os direitos e garantias fundamentais previstos, por mais que o ato praticado seja repudioso e cause repercussão social.

No Brasil, muitas de suas leis penais são questionáveis pelo fato de não serem aplicadas em conformidade com o que está de fato escrito na norma. Uma delas é o tratamento cruel e desumano ao qual o apenado é submetido devido principalmente à falta de estrutura dos estabelecimentos prisionais, sendo este o principal motivo pelo não cumprimento do objetivo real da pena, ao qual toda sociedade sonha em realizá-lo, em que consiste na ressocialização do apenado.

Conforme Moraes (2012) expõe, a ordem constitucional apresenta uma perspectiva de concretizar a correta punição do agente infrator, de forma que haja um devido processo legal que combata as penas cruéis e degradantes. Logo, embora haja firmado um devido processo legal a ser seguido pelo Estado no momento da punição do delinquente, não há estrutura de fato a para a aplicabilidade e efetividade deste devido processo na execução penal.

A violação institucionalizada pelo próprio Estado legislador apresenta, portanto, convergência com o tratamento cruel e degradante, quebrando os paradigmas da punição restaurativa e ferindo a proporcionalidade, sendo repudiada pelo ordenamento, sobretudo, a Constituição Federal e os tratados e convenções internacionais sobre esta matéria.

É evidente que o infrator deverá pagar pelo crime cometido. Entretanto, a partir do momento que surgem os excessos e o tratamento desumano e degradante na execução da pena, permite-se que a aflorar no apenado o sentimento de vingança ao Estado e à própria sociedade. Esse sentimento, sem dúvida, compromete toda a função social da pena e o seu objetivo, ou seja, conforme Foucault (2012), é preciso que a justiça puna em vez de se vingar.

Foucault (2012) faz referência ao princípio da legalidade executiva penal, onde se busca coibir os excessos promovidos por autoridades e pessoas ligadas ao sistema carcerário, visando à proteção e o respeito à dignidade da pessoa humana e a todos os direitos os direitos e garantias fundamentais ainda que o indivíduo esteja com sua liberdade cerceada.

Assim, o Estado deve preocupar-se com a implementação efetiva das funções sociais da pena, investindo em políticas públicas e programas destinados a educação e capacitação do preso ao trabalho dentro e fora dos estabelecimentos prisionais, para que se garanta o retorno do condenado ao bom convívio social, não sendo isto responsabilidade apenas da administração pública, mas de toda a sociedade.

\section{4- A Humanização do Direito Penal e o Papel do CNJ}


Nesse momento se aborda a importância dos direitos humanos na efetivação da reintegração do apenado. Versará, ainda, acerca da falta de compromisso do Estado em exercer suas funções na garantia da aplicação dos direitos humanos na execução da pena, e como as comissões de direitos humanos e o CNJ atuam na solução do problema.

Em uma visão evoluída da justiça punitiva, a retributividade da lei penal deixou de ser considerada e foi adotado um viés humanizado na pena respaldando-se sempre na legalidade e no devido processo legal. A pena deixou, portanto, de ser apenas um castigo ao delito cometido e passou a ter uma função voltada para a ressocialização. Mirabete (2012) expõe que a retribuição da culpa ao infrator como finalidade no direito penal, deu lugar à política voltada para a ressocialização, sendo este trabalho feito após o estudo de sua personalidade, buscando excluir o caráter retributivo da sanção penal.

Embora a LEP brasileira revele, em seu texto, uma função humanitária, dando a entender que a política criminal apresenta uma nova perspectiva para a sociedade, focando-se no sentido humanístico da lei, o próprio Estado é alvo de críticas sociais por conta da possível flexibilidade de suas leis e a humanização de suas penas. Muito pelo contrário, a humanização do direito penal é o principal caminho para o combate à criminalidade, visto que o respeito e tratamento digno nas prisões são a chave para a ressocialização.

A prisão, ao contrário do que ela é atualmente, deve representar um aparelho funcional de disciplina e reeducação dos apenados. No entanto, devido aos problemas já citados, o que existe na verdade é uma relação hierárquica de uns sobre os outros, onde os primeiros isolam, vigiam e maltratam, enquanto os demais sofrem com os abusos e o tratamento desumano.

Pertinente é o que expõe Pena Júnior (2008) a qual ilustra importância da dignidade da pessoa humana em qualquer que seja a situação, de modo que todo indivíduo, independentemente de merecê-la ou não, deverá tê-la preservada.

Todavia, o sistema penitenciário brasileiro necessita imediatamente de um trabalho de reestruturação voltado para a humanização, capaz de promover a mudança do pensamento social a respeito da igualdade e do respeito à dignidade do homem, além de fazer brotar a confiança no sistema punitivo-restaurativo promovido pelo Estado, e assim fazer com que a sociedade assuma também o seu tão importante papel na ressocialização do condenado.

\subsection{O sistema prisional e seu papel socializador}

Frequentemente, tomamos conhecimento, principalmente pelos veículos de comunicação, de intensas críticas à aplicabilidade dos direitos humanos na execução penal. 
Este equívoco é proveniente, unicamente, pelas falhas cometidas pelo próprio Estado em razão de sua omissão. Diante de todos os problemas já apontados, anteriormente, a sociedade, refém da insegurança e da criminalidade, percebe o precipício existente entre efetividade dos direitos humanos em concomitância com a efetividade do sistema punitivorestaurativo brasileiro.

Com isso, essa insegurança social, faz com que a mesma se mostre contrária a qualquer penalidade mais branda ou reintegrativa que seja proporcionada ao delinquente. Isto, porém, é um grande erro, visto que não traz de forma alguma redução da violência e da criminalidade.

Balestreri (2004) aduz que essa insatisfação social é proveniente pelo fato de o Brasil ter um dos piores e mais cruéis sistemas prisionais. Este descaso com as prisões brasileiras faz com que as comissões direitos humanos se empenhem ainda mais nesse ponto, dando uma maior atenção aos detentos e buscando a efetividade de suas garantias.

Além das comissões, o CNJ também tem se mobilizado com a realização de projetos que visam ao aperfeiçoamento da prestação jurisdicional das varas criminais e de execução penal, bem como à reinserção de presos e egressos. A criação de projetos como Grupos de Monitoramento e Fiscalização do Sistema Carcerário - GMF, que tem a função de acompanhar as prisões provisórias e a fiscalização das condições dos presídios, revelada pelos mutirões carcerários realizados nos Estados, e o projeto Começar de Novo, em que se busca a capacitação profissional para os presos egressos no sistema carcerário, promovendo a cidadania e reduzindo o índice de reincidência são alguns dos programas realizados pelo CNJ que visam o melhoramento do sistema carcerário brasileiro.

Segundo o informe da Agência CNJ de Notícias, o sistema penitenciário brasileiro está esquecido, tendo suas unidades prisionais funcionando apenas como depósitos de gente e que em nada contribuem para a recuperação dos apenados. A falha do sistema prisional e os altos níveis de reincidência no Brasil faz com que a aplicação dos direitos humanos nessa área sofra uma aversão social exatamente pelo seu potencial de efetividade na defesa de tais direitos. Não obstante, a mídia, de forma sensacionalista, enfatiza ainda mais a presença desses militantes que buscam a obediência dos princípios humanitários da pena, ampliando ainda mais esse precipício existente entre a aplicação dos direitos humanos e a efetivação do sistema punitivo brasileiro.

Para Zaffaroni (2002), a humanidade e o banimento da crueldade e da tortura estão atrelados à racionalidade republicana na execução das penas. Assevera ainda, que, embora esse seja um princípio hierarquicamente fundamental, é um dos princípios mais ignorados 
pelo Estado.

A humanidade da pena busca fomentar a inserção do apenado e impedir o seu sofrimento excessivo durante o cumprimento de pena. Entretanto, a pena atual resulta em exclusão e discriminação destes que tem concedida de volta a sua liberdade. Retirar o direito à liberdade não significa retirar também os direitos comuns inerentes ao homem, tal qual a dignidade.

Por isso, segundo Guilherme Nucci (2011), o direito penal deve pautar-se pela benevolência e garantia do bem estar da coletividade, incluindo os condenados. Estes seres, portanto, não devem sofrer exclusão social, muito pelo contrário, devem receber ainda mais atenção e serem tratados como seres humanos que são.

Para Greco (2011), devido à situação carcerária a qual presenciamos, a pena de privação de liberdade tem o mesmo efeito dos suplícios que eram realizados em praça pública no século XVIII. Estas masmorras atuais abrigam, como regra, o grupo dos miseráveis e dos que sofreram a exclusão social.

Em outras palavras, é perceptivo que a função da pena não está de forma alguma sendo cumprida. Não acrescenta nada ao indivíduo, apenas destrói e corrompe ainda mais a personalidade daquele que sempre foi desacreditado e humilhado pelos demais. A prisão não tem sequer as garantias do mínimo existencial, desatendendo por completo o principio da dignidade da pessoa humana e transformando o encarcerado em um ser irreconhecível socialmente.

Foucault (2012) narra que chegaríamos ao momento em que, ao olharmos para nossas celas, teríamos vergonha do que fazíamos com seres humanos, estes tratados como animas.

Essa afirmação infelizmente se encaixa perfeitamente na realidade brasileira que, nos dias de hoje, não se sabe ao certo qual o real objetivo da pena. O Estado se comporta apenas como carrasco sanguinário, buscando somente castigar da forma mais cruel o delinquente em retribuição ao delito.

Todavia, a sociedade, frente às omissões do Estado, não deve encaminhasse também para a crueldade, de maneira a punir de forma tão obsoleta. Logo, ser contra a efetividade dos direitos humanos é encobrir a capacidade do Estado de cumprir com suas funções sociais; é estar condizente com as atrocidades para as quais seres humanos diariamente são acometidos; é ser contra a vida, o respeito e a razão; é, acima de tudo, ser desumano.

\section{5- Considerações Finais}


Durante toda a história humana as sociedades organizadas sempre necessitaram de ordem e disciplina para serem construídas e também mantidas.

Nesse sentido, o Estado sempre foi cobrado, principalmente pelos organismos internacionais, pela garantia dos direitos de natureza humana independentemente da situação ao qual o indivíduo esteja inserido.

O direito à liberdade, direito este inalienável que sempre foi objeto de garantia constitucional, oponível até contra o Estado que é quem detém o direito de punir, sempre foi alvo de discussões a respeito de sua restrição pelo Estado e modo de como esta restrição é feita.

Logicamente, para punir, o Estado deverá garantir a obediência dos direitos fundamentais ainda que o indivíduo esteja preso, pois estas garantias transcendem o poder de punição do Estado, sendo que a retirada do delinquente do meio social não significa que este deva sofrer além do que o previsto na sentença.

Ainda que preso, não se permite que o indivíduo seja lesado, devendo o Estado garantir sua integridade física e fornecer estrutura suficiente para que o apenado não sofra nada além do que estabelecido em sua condenação. Esse dever do Estado nasce a partir do momento em que o mesmo se assume o direito de punir o indivíduo infrator pelo devido processo legal, comprometendo-se também à obrigação de custodiá-lo, sendo responsável, portanto, pela sua proteção.

O dever do Estado de primar pela a integridade do preso deve ser dinâmico, de modo que o mesmo esteja seguro de todos os seus direitos a serem preservados, é de grande importância para sua volta à sociedade onde buscará a reconstrução de sua vida social. $\mathrm{O}$ artigo 41 da Lei das Execuções Penais evidencia os direitos do preso a serem considerados, no entanto muitos desses direitos não são de fato preservados pela própria falta de estrutura dos estabelecimentos prisionais.

O desrespeito aos direitos humanos torna-se muito mais evidente nos estabelecimentos prisionais, onde o próprio Estado se mostra incapaz diante da crise penitenciária no país, ignorando todos os princípios e desconsiderando por completo a Lei das Execuções Penais nacional.

Deverá o Estado, além de punir, ser responsável por aquele que se acha preso. A não observância deste preceito configura a desobediência do caput do artigo $2^{\circ}$ da LEP, que é apontado o princípio da legalidade como meio de impedir os excessos na execução da pena e consequentemente inibir os abusos e arbitrariedades cometidas pelo Estado por meio de seus agentes. 
$\mathrm{Na}$ realidade, os problemas penitenciários enfrentados pelo Brasil, não diferente de outros países, ainda estão longe de serem resolvidos. Devido à complexidade do problema, não há uma solução mágica, mas sim uma solução conjunta, como uma máquina que precisa de todas as suas engrenagens para funcionar com perfeição.

Embora o CNJ tenha um papel importante na tentativa de desafogar os presídios brasileiros e de propiciar uma justiça restaurativa eficiente, a realização de mutirões carcerários, apenas, não é suficiente para solucionar o problema.

As soluções, portanto, estão nas mãos de todos dos âmbitos do Poder, seja pela elaboração de leis que se preocupem com a intervenção mínima do Direito Penal, seja na construção de penitenciárias que atendam à dignidade humana e ao cumprimento das funções sociais do Estado, possibilitando o retorno do condenado ao meio social.

A falta de consciência da sociedade perante a situação carcerária é fruto principalmente da falta de compromisso do Estado para com a execução penal da forma como disciplina a LEP. Não há como acabar com a criminalidade de um país sem que o próprio Estado garantidor da pena forneça insumos suficientemente necessários para concretização dos objetivos da punição, quais sejam intimidar o criminoso e reprimir o crime. Além do mais, uma justiça restaurativa efetiva é, sem dúvida, o melhor caminho para a prevenção criminal. É fundamental, portanto, que as autoridades e os poderes constituídos atuem no sentido de buscar todos os meios para a garantia e a preservação do respeito legal que deve ser dado ao recluso, considerando os objetivos da LEP brasileira que vão além do castigo, e que primam pela ressocialização e a reinserção do egresso na sociedade.

\section{Referências}

BALESTRERI, Ricardo Brisolla. Direitos humanos, segurança pública e promoção da justiça. Passo Fundo: Berthier, 2004.

BRASIL. Constituição (1988). Constituição da República Federativa do Brasil.Brasília, DF, Senado, 1998.

BRASIL. Lei De Execução Penal. Disponível em:

<http://www.planalto.gov.br/Ccivil_03/leis/L7210.htm>. Acesso em: 01 Ag. 2018.

_. Presidência da República. Código de Processo Penal. Disponível em:

<http://www.planalto.gov.br/ccivil_03/decreto-lei/Del3689Compilado.htm>. Acesso em: 01 mar. 2018. 
FOUCAULT, Michel. Vigiar e punir história da violência nas prisões. 40. ed. Petrópolis: Vozes, 2012. 36. ed. Petrópolis: Vozes, 2009.

GRECO, Rogério. Direitos humanos, sistema prisional e alternativas à privação de liberdade. São Paulo: Saraiva, 2011.

ISTOÉ INDEPENDENTE. Reincidentes: No Brasil, sete em cada dez expresidiários voltam ao crime. [S.L], 2011. Disponível em:

<http://www.istoe.com.br/reportagens/157533_\%20NO+BRASIL+SETE+EM+CADA+DEZ +EX+PRESIDIARIOS+VOLTAM+AO+CRIME+DIZ+\%20PRESIDENTE+DO+STF?pathI magens\&path=+\&actualArea=internalPage >. Acesso em: 07 Jul. 2018.

LENZA, Pedro. Direito Constitucional esquematizado. 11. ed. rev. atual. ampl. São Paulo: Método, 2007.

MENDES, Gilmar Ferreira. BRANCO, Paulo Gustavo Gonet. Curso de Direito Constitucional. 6. ed. São Paulo: Saraiva, 2011.

MENDES, Gilmar Ferreira. COELHO, Inocêncio Mártires. BRANCO, Paulo Gustavo Gonet. Curso de direito constitucional. 3 ed. rev. atual. São Paulo: Saraiva, 2008.

NUCCI, Guilherme de Souza. Manual de Direito Penal: parte geral: parte especial. 7.ed. São Paulo: Revista dos Tribunais, 2011.

OLIVEIRA, Erival da Silva. Direito Constitucional Direitos Humanos. 2. ed.SãoPaulo: Revista dos Tribunais, 2011.

PENA JÚNIOR, Moacir César. Direito das pessoas e das famílias: doutrina e jurisprudência. São Paulo: Saraiva, 2008.

SILVA, José Afonso. Curso de Direito Constitucional Positivo. $7^{\text {a }}$ ed.rev e ampl. de acordo com a nova Constituição. São Paulo: Editora Revista dos Tribunais, 1991.

VASCONCELLOS, Jorge. Superlotação e más condições de higiene marcam inspeção no presídio Central de Porto Alegre (RS). Agência CNJ de Notícias. Disponível em: <http://www.cnj.jus.br/atos-administrativos/13512:superlotacao-emas-condicoes> . Acesso em: 30 jul. 2018. 
WEIS, Carlos. Direitos Humanos Contemporâneos. 2. ed. São Paulo: Malheiros,2010.

ZAFFARONI, Eugenio Raúl. Criminologia: aproximación desde um margem. Bogotá: Temis, 1993. 